\title{
A causa final nas Disputas metafísicas de Francisco SuAREZ
}

\section{Cesar Ribas Cezar ${ }^{1}$}

Resumo: Nas Disputationes metaphysicae (disp. 23 e 24) Francisco Suarez tenta mostrar que a causa final não é uma projeção do intelecto humano, mas algo real nas próprias coisas e que sem ela não é possível dar uma explicação satisfatória dos fatos observados na experiência. Ele mostra como a causa final age no ser humano, em Deus, nos chamados 'agentes naturais' e no universo como um todo. De fato, a causa final supóe a existência de algo capaz de conhecer um fim e de direcionar suas açóes para ele. Mas isto não significa que o fim está totalmente ausente das operaçōes dos 'agentes naturais', nem que a explicação teleológica nunca faça sentido para eles. Sob certo aspecto há intencionalidade mesmo nas operaçóes dos entes não-racionais, pois toda a natureza está submetida à ação e à racionalidade divina.

Palavras-chave: Metafísica. Causa final. Causa eficiente.

Há, como bem aponta Sydney Penner, uma narrativa histórica bastante difundida, segundo a qual teria havido no pensamento medieval uma adesão geral à tese de que os fins são um tipo de causa presente em todos os fatos empíricos; uma das principais marcas de mudança para o pensamento moderno seria justamente a rejeição deste tipo de causalidade; Suarez teria sido um intermediário nesta passagem ao dar algum tipo de prioridade às causas eficientes e ao diminuir o papel da causa final. ${ }^{2}$ Esta interpretação pode ser encontrada, por exemplo, em C. Schields e D. Schwartz. Para estes, Suarez seria uma figura intermediária entre Aristóteles e Descartes, entre outras

${ }_{1}^{1}$ Professor do Departamento de Filosofia da Universidade Federal de São Paulo (Unifesp), Guarulhos, SP - Brasil. (DD https://orcid.org/0000-0001-6508-2359 E-mail: cesar.cezar@unifesp.br

${ }^{2}$ A standard story has it that medieval philosophy - which in practice means Aquinas - follows Aristotle in a commitment to ubiquitous final causation and that one of the hallmarks of early modern philosophy is a rejection of final causation. When not neglected entirely, Suárez is usually presented as an intermediate figure who departs at least to some degree from medieval philosophy and prepares the way for canonical early philosophers such as Descartes. With respect to the subject at hand, final causation, the standard view seems that Suárez diverges from Aquinas, that he gives some sort of priority to efficient causes [...] and that he diminishes the role of final cause. (FINK, 2015, p. 121).

http://dx.doi.org/10.1590/0101-3173.2019.v42esp.06.p93

This is an open-access article distributed under the terms of the Creative Commons Attribution License. 
coisas, ao negar a realidade da causa final no reino da natureza não-intencional e ao manter os fins como um tipo de causa somente na explicação de açóes intencionais ${ }^{3}$. Também em Vicent Garraud encontramos esta interpretação, pois ele diz que Suarez teria se afastado da visão aristotélica das causas, entre outras coisas, ao reduzir a causa final à intencionalidade de agentes dotados de intelecto e de vontade e ao excluir dos entes naturais tal causalidade. Por fim, Stephan Schmid parece concordar com isto ao afirmar que em Suarez as causas finais só desempenhariam um papel nas açóes de atores racionais, que os 'objetos naturais' não sofreriam nenhuma influência deste tipo de causa, na medida em que não são capazes de conhecimento e que um processo 'natural' poderia receber uma explicação final somente na medida em que Deus - causa eficiente última dele - teria alguma intenção racional na criação ${ }^{4}$.

Esta interpretação, entretanto, é parcialmente contestada por Sydney Penner, quando diz que neste assunto não há uma ruptura entre o pensamento de Suarez e o de Tomás de Aquino, que nele há não só uma presença universal da causa final, mas também uma certa primazia da causa final sobre a causa eficiente ${ }^{5}$. Giancarlo Collacicco, por sua vez, procura mostrar que em Suarez a definição de 'causa' - 'princípio que influi ser em outro’ - inclui o fim, que não há uma primazia da causa eficiente sobre a final e que há uma correspondência entre a causa eficiente e a causa final' .

\footnotetext{
${ }^{3}$ Suarez appears to many historians of philosophy as a sort of bridge figure between scholastic and early modern philosophy. [...] What is clearly true, however, is that he very often develops Aristotelian theses in a manner betraying a willingness to abandon those features of Aristotelianism which were to come in for the harshest treatment by philosophers subsequent to him.' 'Suarez allows that a final cause qualifies as a cause only because and to the degree that it is conceived by an intentional agent. This, then, removes the final causation from the realm of non-intentional nature, even while affirming that final causes play an ineliminable role in psychological explanation, particularly as regards intentional action. (SHIELDS; SCHWARTZ, 2016).
}

${ }^{4}$ Für Suarez spielen Finalursachen nur noch in handlungspsychologischen Kontexten eine Rolle. Für ihn sind Finalursachen jene Ziele oder Zwecke, die endliche rationale Akteure zu ihren Entscheidungen bewegen. Da natürliche Gegenstände nicht erkennen können und Gott als vollkommenes Wesen keinen Einflüssen - auch keinen final-kausalen - unterliegt, spielen Finalursachen auch nur bei der Analyse handlungsteleologischer Sätze, die von endlichen Akteuren handeln, eine Rolle. [...] teleologische Beschreibungen natürlicher Prozesse (werden) auf der Grundlage dispositionaler Essenzen und Gottes Exemplarursachen - das sind die intentionalen Wirkursachen, die der Schöpfung zugrunde liegt - analysiert. (SCHMID, 2011, p. 24).

5 With respect to final causation, however, I wish to push against the prevailing scholarly winds and emphasize Suárez's commitment to ubiquitous final causation. (PENNER, 2015, p. 122). Whether entitled to the claim or not, it does seem clear that Suárez wishes to keep the priority of final causation thesis. This suggests that Suárez's account f causation is closer to Aquinas's than is often thought. (PENNER, 2015, p. 147).

6 All'interno della ratio causae è possibile pensare una vera e própria convenienza tra la causa finale e la causa efficiente. (COLLACICCO, 2014, p. 282). La ratio causae in communi comprende 
Parece, portanto, que há duas interpretaçôes concorrentes sobre Suarez. Uma identifica nele uma primazia da causa eficiente; a causa final não seria propriamente causa real, nem estaria realmente presente em todos os entes, mas somente de modo intencional na mente dos entes racionais e, por analogia, em Deus. Outra não vê nele tal primazia da causa eficiente nem tal redução do fim à sua presença 'intencional' na mente de um agente racional.

Este artigo pretende oferecer alguns elementos para a solução deste conflito interpretativo pela exposição das principais teses presentes nos textos das Disputationes metaphysicae, nos quais ele trata expressamente da causa final.

Francisco Suarez trata da causa final nas disputas 23 e 24 de suas Disputationes metaphysicae. Ele inicia afirmando que a ignorância da causa final fez com que os primeiros filósofos errassem a respeito dos fatos da natureza, pois, sob certo aspecto, ela é a principal entre as 4 causas (eficiente, material, formal e final). Esta ignorância pode ser explicada pelo fato de ser menos evidente para nós o modo de causar da causa final do que o das outras causas. A ratio causandi dela, aquilo que faz a causa final causar, é mais obscura para nós do que a ratio causandi das outras. Suarez, no entanto, segue Aristóteles e afirma que a causa final é, sob certo aspecto, a primeira e a principal entre as causas; logo, não se pode deixar de tentar compreendê-la, mesmo diante da dificuldade, sob pena de deixar de compreender corretamente os fatos da natureza. Assim, ele se propóe a tratar nestas disputas da causa final ${ }^{7}$.

al suo interno tutte le cause che hanno la caratteristica (anche se in modi differrenti) di 'influire' l'essere nell'effetto e tra queste vi sono la forma, la materia, l'efficiente e il fine, le quali hanno pari dignitá o valore quanto a loro essere causa. Anzi Suárez sembra scegliere la definitione di causa come principium per se influens esse in aliud proprio per la possibilitá che essa offre di riferirsi alle quatro cause aristoteliche; c) il rapporto tra le cause supra ricordate e la definizione generale della causa è da Suárez articolato [...] senza far ricorso a modelli di subalternazione o riduzione di una causa , specie l'efficiente, con le altre cause. (COLLACICCO, 2014, p. 289).

${ }^{7}$ Quamvis finalis causa praecipua quodammodo omnium sit atque etiam prior, obscurior tamen est eius causandi ratio et ideo veteribus philosophis paene incognita fuit, ob quam ignorationem in alios errores circa rerum naturalium cognitionem inciderunt, ut Aristot., tract II Phys., c. 8, et I Metaph. et I de Partibus animal. in principio. Ob hanc ergo rationem, licet in superioribus definitum sit finem annumerandum esse inter quatuor causarum genera, ut hoc magis exponamus et difficultates dissolvamos, inquirendum imprimis erit an finis sit causa, deinde quomodo et quid causet, quotuplex etiam sit finis, et quae sit uniuscuiusque causandi ratio. (SUAREZ, F. Disputationes metaphysicae. Ed. Salvador Castellote. Disponível em: www.catedraldevalencia.es/castellote/ Acesso em: 28 junho 2018. Disputa 23, prólogo). As Disputationes metaphysicae serão citadas do seguinte modo: DM 23, 1, 1 = Disputa 23, seção 1 , parágrafo 1 . 


\section{A causa final é real?}

Evidentemente, a primeira pergunta a se fazer é se o fim é uma causa real, se a causa final existe nas próprias coisas e não é só uma projeção do nosso intelecto. Assim começa Suarez. Ele apresenta várias dificuldades que parecem indicar que o fim não é uma causa real. Parece, em primeiro lugar, ser necessário que a causa exista antes do efeito, pois de onde surgiria o efeito senão de algo pré-existente como 'princípio'? Mas o fim, ao contrário, parece vir por último, como o próprio nome indica é algo que surge no 'fim', ele não seria um princípio pré-existente; logo, o fim náo poderia ser verdadeiramente uma causa (DM 23, 1, 1). Em segundo lugar, o fim não poderia ser uma causa real. Por um lado, nada pode ser causa real antes de existir; ora, o fim ainda náo existe no início de uma mudança; portanto, náo pode ser causa real da mudança; por outro lado, quando o fim já existe, não há mais mudança, não sendo preciso postular uma causa dela, nem, portanto, uma causa final (DM 23, 1, 2). Em terceiro lugar, nada é causa real de si mesmo; do contrário, algo existiria antes de existir; assim, uma forma não pode ser causa de si mesma; ora, o fim parece ser a forma adquirida no final da mudança; logo, o fim não pode ser causa de si mesmo. Além disso, se algo é causa real de outro, então há uma distinção real entre estas duas coisas; mas isto é impossível entre o fim e o efeito, pois no início o fim não existe realmente e, portanto, não pode se distinguir realmente de nada e no final ele já é realmente idêntico ao efeito e também não pode ser realmente distinto dele (DM 23, 1, 3). Em quarto lugar, a palavra 'fim' pode ser entendida de duas maneiras: ou como o termo para o qual tende a mudança (o termo do movimento de uma pedra, por exemplo, seria o centro da terra) ou como aquilo que atrai um agente à ação (um banho atrai um homem); ora, o termo para o qual tende uma mudança não parece ser causa real dela, pelo contrário, parece ser mais o efeito de outras causas do que a origem da mudança e aquilo que atrai um agente para a ação parece mover o agente só metaforicamente, isto é, não parece mover realmente. Em nenhum dos casos, portanto, o fim pode ser entendido como causa real (DM 23, 1, 4). Em quinto lugar, foi postulada a realidade da causa final para explicar o fato de náo ser fortuita a operação dos chamados agentes naturais, mas constante e determinada - uma pedra, por exemplo, tende a se mover para baixo não fortuitamente, mas constantemente, como para um fim determinado. Ora, para se explicar esta constância não parece ser preciso postular tal realidade da causa final, como se aquele lugar de algum modo atraísse a pedra; basta dizer que a pedra tende por uma inclinaçáo natural para aquele lugar, basta dizer que tal natureza tem em sua causalidade eficiente esta 
propensão ou esta inclinação para explicar a constância de sua operação. $\mathrm{O}$ mesmo raciocínio pode ser aplicado ao ser humano. Ele se moveria para tal objeto por uma propensão natural de sua causalidade eficiente para tal objeto e não por alguma ação causal do objeto sobre ele. Não parece, portanto, ser preciso postular a realidade da causa final (DM 23, 1, 5). Por fim, em sexto lugar, é difícil explicar sobre o que agiria a causa final. Ela não pode agir sobre o agente, pois ela não causa nada nem nos chamados agentes naturais, cujas propensóes naturais são sempre as mesmas, nem em Deus, que só pode ser causa, nunca efeito. Ela também náo causa nada no efeito, pois, como vimos acima, o fim é o próprio efeito e nada pode ser causa de si mesmo. Assim também parece impossível postular a realidade da causa final (DM 23, 1, 6).

Diante destas dificuldades, Suarez afirma categoricamente que o fim é uma causa real, verdadeira e distinta das outras causas. Sócrates, Platão e Aristóteles afirmaram isto. Também o fato de que a expressão 'porque' é usada na linguagem comum para indicar a finalidade é sinal de que o fim é uma causa real ${ }^{8}$. Além destas persuasões, há, entretanto, um argumento racional decisivo.

O 'argumento decisivo' de Suarez em favor da realidade da causa final é o seguinte: todo efeito de uma causa eficiente depende realmente da causa eficiente da qual ele surge; ele só existe e só é o que é, se sua causa eficiente realmente operar de determinado modo, produzindo-o; do contrário, se a causa eficiente não operasse de determinado modo, o efeito não seria o que ele é. Ora, a causa eficiente só opera de modo determinado se realmente tender para algo, pois, se não tendesse para algo, agiria de modo indeterminado e o efeito não seria o que é. Assim, a causa eficiente realmente depende de um fim determinado para agir de modo determinado. Assim também, o efeito, para ser o que é, também depende realmente de um fim, pois ele depende realmente da causa eficiente e a causa eficiente depende realmente de um fim

\footnotetext{
${ }^{8}$ Nihilominus statuenda est conclusio certa finem esse veram, propriam ac realem causam. Hoc est receptum dogma et quasi primum principium in philosophia et theologia; illud docuit Aristot., II Metaph., c.3, et lib. XI, c.1 et II Phys, c.1 et sequentibus; et ante illum docuerat Plato in Phaedone ubi in eamdem sententiam refert Socratem [...] Ratio autem sumi imprimis potest ex communi modo loquendi de fine et de causa; nam finis esse dicitur propter quem aliquid fit vel est; [...] unaquaeque enim res propter causam suam dicitur habere esse; ergo signum est finem habere rationem causae. (DM 23 1, 7).
} 
para agir deste modo e não de outro. $\mathrm{O}$ fim é, portanto, uma causa real de qualquer efeito?

Para Suarez, portanto, a causa final é o outro lado da causa eficiente. Uma não poderia existir sem a outra. Uma causa eficiente só é uma causa eficiente na medida em que produz um efeito determinado; se ela não produzisse nenhum efeito determinado, ela não produziria nada e não seria uma causa eficiente. Ela é direcionada para um efeito e se não fosse direcionada para um efeito, nada seria produzido. O efeito só é determinado, porque há um fim. Não há, portanto, uma causa eficiente sem um fim. E assim como temos que postular a realidade da causalidade eficiente para explicar a existência real de qualquer coisa (exceto Deus), pois, do contrário, teríamos que afirmar que algo surgiu do nada, assim também temos que postular a realidade da causalidade final para explicar a existência real de qualquer coisa (exceto Deus), pois sem ela teríamos que negar a realidade das causas eficientes que produziram as coisas, pois sem a causa final as causas eficientes não produzem nada determinado, isto é, não produzem nada. Negar a realidade da causalidade final implica em negar a realidade da causalidade eficiente ${ }^{10}$.

Depois deste 'argumento decisivo', Suarez se propõe a afastar as dificuldades acima apresentadas. Ele distingue três tipos de causas eficientes: Deus, o primeiro e supremo intelecto agente; os agentes intelectuais criados, sobretudo os seres humanos, e os chamados agentes naturais, que carecem de intelecto, sejam dotados de conhecimento e apetite sensível ou não. Como dentre estes três tipos de agentes o mais conhecido por nós é o ser humano, ele se propóe primeiro a esclarecer estas dificuldades nele, e só depois explicar como a causa final se dá em Deus e nos agentes naturais ${ }^{11}$.

\footnotetext{
9 Praeterea causa efficiens, nisi temere agat, alicuius gratia agere debet; ergo et ipse effectus causae efficientis, ut per se ab illa fieri possit, intrinsece postulat ut alicuius gratia fiat; ergo talis effectus sicut per se pendet $\mathrm{ab}$ eficiente, ut a quo fit, ita in suo genere per se pendet ab aliquo cuiús gratia fit; ille autem est finis; ergo per se pendet a fine; ergo e contrario finis est vera causa eius rei quae propter finem fit. (DM 23, 1, 7).

${ }^{10}$ As explicaçôes de Stephen Schmid sobre a relação da causa final com a causa eficiente em Tomás de Aquino também se aplicam a Suarez: "Der Finalursache kommt deshalb ein Primat vor den anderen Ursachen zu, weil das Ziel 'in allen Ursachen Ursache der Ursächlichkeit' ist. [...] Etwas wird also nur dadurch wirkend oder oder zu einer Wirkursache dass es auf eine bestimmte Wirkung abzielt. Würde etwas nicht auf eine bestimmte Wirkursache abzielen und wäre es in diesem Sinne nicht auf eine bestimmmte Wirkung festgelegt, so wäre dieses etwas selbst keine bestimmte, und damit keine Wirkursache. Das Ziel legt die Identität einer Wirkursache fest.” (SCHMID, 2011, p. 51-52).

${ }^{11}$ Primum et supremum est intellectuale agens increatum, quod est solus Deus. In secundo ac medio ordine sunt agentia intellectualia creata, inter quos nobis notiores sunt homines [...]. In tertio et infimo ordine sunt agentia naturalia seu intellectu carentia [...] Causalitas ergo finis, licet suo modo
} 


\section{A causa final no Ser humano}

No ser humano, a realidade da causalidade final pode ser comprovada também pela experiência direta. Com efeito, quando o ser humano age de modo humano, isto é, de modo racional e livre, ele experimenta em si mesmo que age tendo um fim como intenção, isto é, que ele direciona suas açóes para este fim e que escolhe certas açóes como meios para este fim. Ao intender tal fim, ele experimenta que é movido por ele, seja tendendo diretamente para ele, seja escolhendo e executando açóes intermediárias. Ora, estes movimentos não são ficçôes de minha imaginação ou do meu intelecto, mas são reais. Sendo reais, também é real a origem deles, isto é, a ação causal que o fim exerce sobre mim. No ser humano, portanto, é mais manifesta a realidade da ação causal do fim ${ }^{12}$.

Além disso, ao experimentar que escolhemos e executamos certas açóes visando algo além delas (faço dieta, por exemplo, para ter saúde), constatamos que é possível e necessário estabelecer uma ordem entre os fins. Um movimento tendente a um fim imediato pode ser parte de outro movimento tendente a outro fim. Muitas vezes é até mesmo necessário dizer que o fim imediato está subordinado a outro fim. Nestes casos, não seria suficiente uma explicação que se limitasse a indicar o fim imediato e que ignorasse a existência de outros fins, os quais fazem com que o fim imediato seja um fim. Pois o fim imediato não seria capaz de originar o movimento por si só, isto é, sem os outros fins. Esta ordem de dependência entre os fins aparece com maior evidência nas açóes humanas (DM 23, 1, 8).

Quanto à primeira dificuldade, no ser humano fica claro que o fim também é algo que está presente antes do efeito e que, portanto, pode ser princípio e causa do efeito; pois o início do movimento humano se dá quando há uma intenção de um fim; o fim enquanto intencionado, portanto, está presente antes do efeito, mesmo que na execução seja o último a aparecer (DM 23, 1, 10).

locum habeat in actionibus horum omnium agentium, tamen in creatis agentibus intellectualibus nobis notior est $[\ldots]$ et ideo in illis peculiariter declarabimus hanc causalitatem finis et expediemus difficultates circa eam insurgentem; postea vero de aliis agentibus dicemus. (DM 23, 1, 8).

${ }^{12}$ Constat enim nobis experientia intendere nos, cum humano modo, id est, libero et rationali operamur, certum aliquem finem in quem actiones nostras dirigimus et propter quem media eligimus; movemur ergo a fine, tum ad dilectionem seu intentionem sui, tum ad eligenda et exsequenda media propter illum; haec autem motio aliquid est in rerum natura; non est enim aliquid imaginarium vel fictum per intellectum; et aliquod genus causalitatis est, quandoquidem est origo operationum realium; est ergo finis vera et realis causa. (DM 23, 1, 8). 
Quanto à segunda dificuldade, no ser humano também é fácil entender que o fim pode ser uma causa real, mesmo não existindo em ato antes da produção dele como efeito, pois a mente que o apreende e o intenciona existe em ato. $\mathrm{O}$ fim que existe intencionalmente num sujeito existente em ato pode, portanto, exercer uma influência real sobre a causa eficiente humana, fazendo com que ela produza seu efeito. E é falso dizer que o fim não pode exercer nenhuma ação causal depois que ele já foi produzido como efeito, pois não haveria mais mudança nem seria necessária causa da mudança. Pois uma vez produzido o fim-efeito, só deixa de existir o movimento em direção a ele chamado desejo, mas não aqueles movimentos em direção a ele chamados de deleite e repouso; só há deleite e quietude na presença daquele efeito, porque há uma tendência para ele (se não houvesse tal tendência, não haveria nem deleite nem quietude). E se continua a haver tal tendência, então o fim continua a exercer sua ação causal (DM 23, 1, 11).

Quanto à terceira dificuldade, nas açôes humanas não há, propriamente falando, algo que é causa real de si mesmo, como se existisse antes de existir. $\mathrm{O}$ que está presente inicialmente é a intenção do fim ou o fim enquanto intencionado. Este causa um desejo do fim ou algum outro tipo de movimento em relação ao fim, portanto, causa algo distinto de si mesmo. E o fim produzido no final não é o mesmo o fim intencionado no início. Não há, portanto, uma forma produzindo a si mesma. Deste modo também podemos reconhecer uma distinção real entre a causa, o fim intencionado, e o efeito, o desejo ou outro movimento (DM 23, 1, 12).

Quanto à quarta dificuldade, quando se diz que o fim move de modo metafórico, não se quer dizer que sua influência não seja real, mas somente que ele não move do mesmo modo que a causa eficiente. Como o modo de causar da causa eficiente nos aparece mais claramente, os termos 'causar', 'mover', 'agir' tiram seu significado inicialmente dele e o uso destes termos para o fim é secundário ou metafórico, mas isto não significa que a moção do fim não seja real (DM 23, 1, 14).

Quanto à quinta dificuldade, no ser humano não parece possível explicar as açóes propriamente humanas sem nenhuma causalidade real do fim. Embora haja no ser humano causalidades eficientes com propensôes e inclinaçóes a determinados efeitos, estas causalidades eficientes não agem sem a presença (pelo menos intencional) do fim. Assim, não se pode dizer que o fim não exerce nenhum tipo de causalidade real, pois o direcionamento de 
uma causalidade eficiente para um efeito determinado só se efetiva na presença do fim (DM 23, 1, 15).

Quanto à sexta dificuldade, é claro que o fim exerce uma ação causal sobre o agente no caso do ser humano, mais especificamente, sobre sua vontade, que é a principal causa eficiente das açôes propriamente humanas (DM 23, 1, 15).

Suarez esclarece então muitas outras dificuldades que podem surgir em relação à causa final no ser humano, o que deixaremos de lado neste artigo por razóes de espaço. Mas vale a pena destacar um destes esclarecimentos. Como dito acima, o fim só move o apetite enquanto conhecido e intencionado, mas isto não significa que não é o fim realmente existente que é buscado. Com efeito, quando alguém busca, por exemplo, a saúde, o que ele busca é que a saúde exista realmente nele e não só o conhecimento da saúde. $\mathrm{O}$ fim enquanto conhecido e intencionado está direcionado para o fim atualmente existente. A finalidade do fim conhecido e intencionado é o fim existente. Portanto, o que move o apetite em última instância é a existência real do fim, não no sentido de que ele já exista tal no início, mas no sentido em que é a sua existência real que é intencionada (DM 23, 1, 14).

\section{A causa final em Deus}

$\mathrm{Na}$ medida em que só conseguimos pensar a realidade divina a partir das criaturas, especialmente do ser humano, as soluçóes acima apresentadas podem ser aplicadas a Deus. Mas Suarez apresenta uma nova dificuldade em relação à presença da causalidade final nas operações divinas: nos seres humanos, o fim - conhecido e intencionado - move primeiramente a vontade humana, fazendo com que esta causa eficiente produza seu ato, a partir do qual as outras causas eficientes presentes no homem produziráo seus atos respectivos. Ora, Deus não pode ser movido por nada. Com efeito, a causa primeira não pode ser nunca efeito. Logo, também sua vontade náo pode ser movida por nada. Logo, não parece haver nenhum tipo de finalidade nas operaçôes divinas (DM 23, 9, 1).

Para enfrentar esta dificuldade, Suarez faz a seguinte distinção: uma coisa é perguntar sobre a causalidade de um fim nos atos da vontade divina enquanto eles lhe são imanentes; outra coisa é perguntar sobre a causalidade 
de um fim nos atos da vontade divina enquanto eles se projetam para fora dela, isto é, nos efeitos dela (DM 23, 9, 2).

Quanto à primeira pergunta, a resposta é: nenhum fim exerce causalidade sobre os atos da vontade divina enquanto lhe são imanentes. Assim como não há nenhuma causa eficiente dos atos livres da vontade divina, sendo ela causa eficiente primeira, assim também não há verdadeiramente nenhum fim exercendo causalidade sobre ela, pois, se não há causa eficiente, não há porque postular uma causalidade final, que é postulada para explicar o movimento da causa eficiente (DM 23, 9, 3-4).

Assim, quando se diz que Deus ama a si mesmo e as outras coisas movido por sua bondade, isto náo pode ser entendido como algo verdadeiro e real em Deus, pois assim como não há nele nenhuma distinção real entre potências e atos, assim também não há nele nenhuma movimentação real. Propriamente falando, portanto, é errado dizer que Deus é o fim de si mesmo, a não ser que se entenda com isso somente que Ele não tem outro fim, assim como é errado dizer que Deus é causa eficiente de si, a não ser que isto signifique somente que não há outra causa eficiente. Quando se diz que Deus ama a si mesmo e as outras coisas movido por sua bondade, isto se dá porque só podemos conceber e explicar a realidade divina comparando-a com as criaturas, mais especificamente, com o ser humano, onde o fim realmente move. Este modo de falar é, entretanto, sumamente metafórico (DM 23, 9, 3/5).

Quanto à segunda pergunta, deve-se dizer que também nos atos da vontade divina enquanto se projetam para fora dela, isto é, nos efeitos dela, não há, propriamente falando, uma causalidade final, isto é, um fim que move a causa eficiente a agir, mas se pode dizer que há um fim nela no sentido de um termo para o qual tende a operação. Neste sentido, pode-se dizer verdadeiramente que Deus age tendo um fim em vista, ou seja, que Deus cria e ordena todas as coisas visando um fim, isto é, algo para o que tudo tende (DM 23, 9, 8).

Pode-se até mesmo falar que o fim para o qual tudo tende é, em Deus, verdadeiramente uma causa final no seguinte sentido: no ser humano, dizemos que o fim é causa porque a bondade dele move a causa eficiente a produzir seu efeito; ora, o que dá ao fim a capacidade de mover é sua bondade (se ele não fosse bom, não atrairia e não moveria); logo, o que faz um fim ser causa final é principalmente a sua bondade e não o fato de haver uma causa eficiente a ser movida. Assim, pode-se falar que o fim é em Deus causa final, mesmo não 
havendo nele uma causa eficiente a ser movida, pois o que faz um fim ser causa final é principalmente sua bondade intrínseca (DM 23, 9, 9).

Assim também pode-se dizer propriamente que os efeitos de Deus têm uma causa final. Não no sentido em que há algo que move a vontade divina a criar e ordenar o universo, mas no sentido que há um fim para o qual tende o universo criado e que este fim pode ser propriamente chamado de causa final do universo, pois é a bondade intrínseca do fim que faz com que ele seja uma causa final. Mesmo não visando nenhum fim para Si mesmo, pois Deus não pode adquirir nenhum bem que já não possua, Ele visa um fim bom para as criaturas. Mesmo não havendo em Deus uma causa final, há uma causa final nas criaturas. Como veremos abaixo, ela só pode ser a própria bondade divina, pois nada menor que a comunicação e manifestação de sua bondade infinita é compatível com a perfeição de Deus (DM 23, 9, 10-12).

\section{A Causa final nos agentes naturais}

Suarez trata então dos chamados agentes naturais, isto é, de todos aqueles entes que agem sem intelecto e sem vontade livre e que não podem ordenar conscientemente, por assim dizer, suas operaçóes para um fim. Ora, a causalidade final só se dá quando há um direcionamento para um fim. Parece, portanto, que as operaçóes destes agentes não são ordenadas a nenhum fim, que, na medida em que deles provêm, também não o são os efeitos deles e que, portanto, não há um fim exercendo sobre eles qualquer tipo de causalidade ${ }^{13}$. Isto levou alguns pensadores, como Anaxágoras, Empédocles, Demócrito, Epicuro, a afirmar que as obras da natureza em geral surgiram do acaso ou do encontro fortuito entre os átomos ou de uma necessidade da matéria. Mas, como mostra Aristóteles, esta posição é insustentável ${ }^{14}$. A experiência nos mostra fatos que não podem ser explicados pelo acaso. Observamos, por exemplo, um pássaro - um ente sem intelecto e sem vontade livre - juntar palhas. Não é plausível que ele 'por acaso' junte a palha, que 'por acaso' disto surja um ninho, que 'por acaso' proteja os ovos, etc. Também não é plausível

\footnotetext{
${ }^{13}$ Haec quaestio generalis est de omnibus agentibus carentibus intellectu et voluntate, quibus omnibus commune est ut non possint actiones suas vel media ad finem referre seu ordinare. Et hinc oritur dubitandi ratio; nam propria causalitas finis non est sine hac ordinatione. (DM 23, 10, 1).

${ }^{14}$ In hac re fuit antiqua opinio veterum philosophorum negatium opera naturae provenire ex intentione alicuius finis, sed casu ita constituisse, vel ex concursu atomorum temere ita concurrentium, vel ex necessitate materiae, ut citato loco II Phys. C.7 et 8, contra Anaxagoram, Empedoclem, Democritum et Epicurum disputat Aristoteles. Quae sententia adeo absurda est ut refutatione non egeat. (DM 23, 10, 2).
} 
dizer nem mesmo que o fogo, a pedra, etc. - outros tipos de entes sem intelecto e sem vontade livre - operem 'por acaso', pois observamos que suas operaçóes tendem regularmente para um fim determinado e só deixam disto, se forem impedidos por algo externo - observamos, por exemplo, que uma pedra regularmente se move para baixo e só deixa de fazer isto se é impedida por algo exterior. Ora, se este movimento fosse fruto do 'acaso', a pedra se moveria para cima, para baixo, para os lados 'fortuitamente', o que não observamos. Por fim, observamos a beleza do universo como um todo, a harmonia e a ordem entre suas partes, coisas que não podem ser explicadas como fruto 'do acaso'. Assim sendo, se não quisermos negar a realidade daquilo que a experiência nos mostra, não podemos dizer que as operaçôes destes entes sejam realmente frutos do 'acaso', mas que há realmente algum tipo de finalidade neles ${ }^{15}$.

Entretanto, se não pode haver dúvida sobre a presença de algum tipo de finalidade nas operaçóes dos chamados agentes naturais, há dúvidas sobre 'como' o fim está presente nestes diversos casos. Mas para solucionar estas dúvidas, cabe distinguir os diversos casos. Uma coisa é explicar como um fim está presente na ordenação do universo como um todo, tornando-o belo e harmonioso; outra coisa é explicar como há um fim nas operações próprias de cada tipo de agente natural. Nestes, por sua vez, deve-se diferenciar os animais irracionais, que possuem algum tipo de conhecimento, dos entes totalmente destituídos de conhecimento, como o fogo e as plantas (DM 23, 10, 2-3).

Vejamos primeiro as operaçôes dos entes totalmente destituídos de conhecimento. Não há dúvida de que há algum tipo de finalismo nelas. Por um lado, como dito acima, não há causalidade eficiente sem um fim, isto é, uma causa eficiente que não tende para nada, não produz nada e, portanto, não é uma causa eficiente. Por outro lado, sem o fim determinado fica difícil explicar a regularidade observada nas operaçôes destes entes. A dúvida está no seguinte: tendo em vista o fato de que estas operaçóes tendem para um fim,

\footnotetext{
${ }^{15}$ Atque hoc confirmat experientia; nam videmus hirundinem ita congregare paleas vel aliquid simile efficere sicut expedit ad finem suum, et sic de aliis (DM 23 10, 1). Solum ergo hic inquirimus de actionibus naturalium causarum, sive illae sint omnino particulares, ut ignis, plantae etc. sive aliquo modo universales, ut caeli. De quibus praeterea certum et clarum est non casu aut contingenter certas actiones operari, sed unumquodque agens naturale ex propensione propriae naturae habere definitam operationem, et operandi modum, ac certum terminum in quem per suam operationem tendit. Quod etiam est evidens experientia, nam lapis sua motu naturali semper fertur deorsum, ignis semper calefacit, ex diversis seminibus diversa viventia procreantur, et alia potentiae et organa ad hoc munus, aliae vero ad alia destinatae sunt. (DM 23, 10,3). Atque hoc evidentissime docet ipsa universi pulchritudo et mira partium eius et causarum omnium consenso et ordinatio. (DM 23, 10, 2).
} 
podemos propriamente dizer que elas foram causadas por uma causa final? (DM 23, 10, 4).

Parece que não. Eles não podem ser movidos pelo fim. Com efeito, os seres humanos podem ser movidos pelo fim enquanto conhecido, mas estes entes não possuem nenhum conhecimento do fim (DM 23, 10, 4).

Suarez então responde: propriamente falando devemos dizer que estas operaçóes foram causadas por uma causa final. Não na medida em que elas foram produzidas por estes entes considerados neles mesmos, mas na medida em que elas também foram produzidas por Deus, o agente primeiro, que está presente em toda e qualquer operação. Ou seja, na medida em que as operaçóes destes entes naturais são causadas por um agente superior e que as operaçóes deste agente superior são causadas por um fim, então, em última instância, estas operaçóes foram causadas por um fim. Podemos dizer propriamente que o alvo é causa real do movimento da flecha, porque o arqueiro é realmente causa do movimento da flecha e o alvo é realmente causa (final) do movimento do arqueiro. Com efeito, o movimento do arqueiro (e o da flecha) não seria tal como é, se o alvo não existisse. Assim, nas operaçóes destes entes, mesmo não havendo causa final na medida em que eles são a causa próxima destas operaçóes, mas somente uma tendência para um termo determinado, há uma causa final na medida em que Deus é causa eficiente deles. Como Deus é a causa eficiente principal, e ele é uma causa intelectual que age tendo algum fim em vista, então, propriamente falando, deve-se dizer que há uma causa final nestas operaçóes ${ }^{16}$.

Além disso, não é possível explicar porque uma coisa é o que é, mesmo daquelas coisas que não são dotadas de nenhum tipo de conhecimento, sem a presença da causa final. Uma coisa é o que é não pela matéria, pois a matéria em si mesma é neutra. A matéria em si não tem esta ou aquela disposição, não tem estas ou aquelas partes, não tende para isto ou para aquilo, nem opera desta ou daquela forma. Uma coisa só é o que é pela forma, a forma 'pedra', por exemplo. A coisa só tem tais partes, tais disposiçôes, só é causa eficiente disto e daquilo, só tem tais tendências e tais operaçóes pela sua forma. Mas só podemos entender que uma coisa tenha tal forma por causa de um fim, seja

\footnotetext{
${ }^{16}$ Nihilominus, proprius modus loquendi in hac materia est actiones horum agentium naturalium esse propter finem et esse effecta causa finalis. Non tamen ut praecise egrediuntur ab ipsis naturalibus agentibus, sed ut sunt a primo agente, quod in omnibus et per omnia operatur. (DM 23, 10, 5). Adaequatum enim principium harum actionum non est solum proximum agens naturale, nisi forte secundum quid, scilicet in tali ordine; tamen, absolute praecipuum est prima causa; ideoque in adaequato principio talium actionum includitur intellectualis causa intendens finem earum. (DM 23, 10, 6).
} 
ele a própria conservação, seja a conservação de sua espécie, seja algum outro tipo de comunicaçáo do seu ser. Pois, do contrário, teríamos que dizer que a forma surgiu 'por acaso', ou seja, que a ordem surgiu da ausência de ordem, que algo (a ordem) surgiu do nada (ausência de ordem), o que é absurdo. Assim, mesmo no caso dos entes destituídos de conhecimento, sempre haverá um fim. Como não foram eles mesmos que se ordenaram a um fim, mas sua causa eficiente primeira, seu fim último deve ser algo distinto de suas próprias operaçóes e que é conhecido pela causa primeira (DM 23, 10, 7).

Alguém poderia objetar assim: para explicar o fato de os agentes naturais operarem do jeito que o fazem, basta que eles tenham neles mesmos uma certa necessidade natural, e que náo é necessário postular nem uma causa final para eles nem um Deus que ordene as operaçóes deles. Esta hipótese só seria plausível para Suarez se eles fossem o que são por si mesmos, isto é, se eles não dependessem de uma causa eficiente primeira para ser. Ora, não é possível negar a causalidade eficiente de Deus. Todas as coisas (exceto Deus) dependem em última instância de uma causa eficiente primeira para ser. Assim, elas só possuem tais necessidades naturais porque Deus as fez assim. Mas esta causalidade eficiente primeira não opera sem um fim. Logo, todas elas dependem em última instância de um fim para ser. E como a causalidade eficiente de Deus não é indireta, como afirmam alguns intérpretes de Aristóteles, mas direta e concomitante com as causalidades eficientes das coisas criadas, também é direta a ordenação de cada coisa singular para o fim último da criação (DM 23, 10, 8-9).

Esta última conclusão, entretanto, parece ser falsa. A experiência, com efeito, nos mostra frequentemente coisas que não produzem o efeito próprio de sua espécie e náo atingem o fim para o qual aparentemente tendem pedras que não vão para baixo, plantas que não crescem, 'monstros' em todas as espécies de animais, etc. Estes 'erros' da natureza parecem indicar que nem tudo que existe, existe por causa de um fim, pois eles existem e de fato não foram ordenados para seu fim; aparentemente, portanto, Deus não ordena diretamente todas as coisas para um fim (DM 23, 10, 8).

Suarez responde assim: se não houvesse um fim próprio para cada espécie de coisa, não haveria 'erros' na natureza. Só podemos dizer que uma flecha errou o alvo, se existir o alvo; se o alvo não existir, nenhum movimento da flecha seria errado. Do mesmo modo, só podemos dizer que uma coisa não produziu o efeito próprio da sua espécie e que aparentemente não alcançou o fim para o qual tende, se existir um efeito próprio desta espécie 
de coisa. Do contrário, nenhum movimento seria errado. Um 'monstro' só é um 'monstro' na medida em que a coisa se distancia da forma própria de sua espécie. Em outras palavras, não faz sentido dizer 'o bem não existe porque o mal existe', pois só podemos dizer que algo é mau comparando-o com algo bom (DM 23, 10, 11).

Suarez continua: a coisa só deixa de produzir o efeito próprio de sua espécie se algo exterior a ela a impede. Exemplos: uma pedra só deixa de ir para baixo porque uma trave a impede de descer; uma árvore não cresce porque não houve água suficiente; um animal gera um 'monstro' porque um vírus deformou o feto (DM 23, 10, 11).

Mas quando uma coisa não produz o efeito próprio de sua espécie, isto não significa que esta coisa não atingiu o fim dela? Não, pois Deus visa primeiramente a beleza do todo e não a do indivíduo isolado. Ele só quer que esta coisa individual produza seu efeito próprio na medida em que isto contribui para a beleza e a variedade do todo criado. Muitas vezes, porém, o que contribui para a beleza do todo é justamente a coisa deixar de produzir seu efeito próprio. Neste caso, de modo algum deve-se dizer que a coisa náo alcançou seu fim; pelo contrário, devemos dizer que ela alcançou seu fim maior (que é contribuir para a beleza do todo) justamente porque deixou de produzir seu efeito próprio. Muitas vezes, portanto, o efeito próprio de uma coisa deve ser separado do fim maior dela. Assim sendo, nunca se pode dizer que uma coisa existe sem um fim, pois sempre uma coisa será o que ela é, mesmo um 'erro' da natureza ou um 'monstro', devido a um fim particular, que está submetido ao fim geral que é a variedade e beleza do todo. Evidentemente, isto não significa que nós, seres humanos, saibamos qual é este fim particular e como ele se liga ao fim geral. Em última instância, só a causa primeira sabe porque uma coisa em particular produz ou deixa de produzir tais efeitos, só a causa primeira sabe de que modo uma coisa particular contribui para a realização do fim último da criação (DM 23, 10, 10-11).

Tendo tratado dos entes totalmente destituídos de conhecimento, resta ver os chamados animais irracionais. Não há dúvida que a causalidade final está presente em suas operações. Não se pode, por exemplo, descrever corretamente o que um pássaro está fazendo ao juntar palha sem dizer que ele junta palha 'para' construir um ninho. A dúvida está no seguinte ponto: as operaçóes destes animais podem ser igualadas às operaçóes humanas? 
Parece que sim. Estes animais, com efeito, se movem quando reconhecem algo como sendo conveniente para eles. Eles são, portanto, movidos por um fim enquanto 'conhecido'. Eles então são movidos a realizar certas operaçóes que são meios para a obtenção daquele fim. Mas eles se movem para estes meios só porque 'reconhecem' que estes meios são adequados para o fim buscado. O pássaro, por exemplo, junta palhas, porque 'reconhece' que a palha é adequada para a construção de um ninho. Se não 'reconhecesse' isto de nenhuma maneira, não haveria uma razão pela qual ele juntasse palhas e não pedras. Assim sendo, parece que estes animais são capazes de conhecer a utilidade de algo tendo um fim em vista e que eles são capazes de ordenar suas operaçôes para um fim. Parece, portanto, que estes animais também possuem a mesma capacidade racional que os seres humanos, ainda que ela esteja presente neles de modo mais fraco, e que suas operaçóes são iguais às dos homens (DM 23, 10, 12).

Mas isto é falso. A razão dos seres humanos não opera sempre do mesmo modo; ao deliberar sobre o fim a ser realizado, eles podem escolher um meio ou outro, o que não acontece com os animais irracionais. Ao buscar construir um local protegido, por exemplo, o ser humano pode inicialmente considerar a palha como meio para isto, mas depois, vendo que não há palha disponível ou que a palha não é tão adequada, ele passa a considerar o barro como meio e o escolhe. Isto não acontece com o animal irracional. $\mathrm{O}$ pássaro, cuja espécie constrói locais protegidos com palha, não é capaz de considerar outro material como meio e, caso não haja palha disponível, não constrói o ninho. Ele não é capaz de agir de modo diferente, o que mostra que ele é movido por algum impulso natural, e não pela razão. Isto acontece porque o animal irracional não é capaz de reconhecer um meio como meio e um fim como fim. Ao recolher a palha, ele não sabe que ela é um meio para um fim. Para ele, a palha é como que um fim, pois é algo que pura e simplesmente o atrai. Não sendo capaz de reconhecer que um meio é só um meio, ele também não é capaz de reconhecer a possibilidade de haver outros meios nem de ordenar os meios para um fim. O ser humano, ao contrário, é capaz de reconhecer formalmente meios e fins. Ele é capaz de saber, por exemplo, que a palha é só um meio para o fim, que há outros meios. Assim ele é capaz de ordenar as operaçóes como meios para um fim. E mesmo aquelas operaçóes dele, que parecem ser causadas só pelo impulso natural, são em última instância contaminadas pela sua racionalidade e ordenadas como meios para um fim. Um homem, por exemplo, busca ter relaçóes sexuais com uma mulher não só pelo impulso natural, mas também porque sua razão julga que isto é um meio para um fim (felicidade) (DM 23, 10, 13-15). 
Portanto, as operaçóes dos animais irracionais náo podem ser igualadas às operaçóes dos seres humanos. Estritamente falando, elas são mais próximas das operaçóes dos entes totalmente destituídos de conhecimento do que das operaçóes dos seres humanos, pois os animais irracionais, tal como aqueles entes, não ordenam eles mesmos os meios para os fins. Esta ordenação já está dada neles. Como vimos acima, Deus os fez assim, tendo um fim em vista, mas este fim, eles mesmos desconhecem.

\section{A causa final no universo como um todo}

Agora podemos passar para a última questão: já vimos que todo ente do universo criado tem uma causa final própria, pois eles não seriam o que são sem ela. Mesmo aqueles entes que não realizam o efeito próprio de sua espécie, como uma árvore que náo cresce, uma ave que náo voa, um ser humano que não chega a usar sua racionalidade, tem uma causa final própria, isto é, eles são o que são devido a um fim, que em última instância é conhecido por Deus. Se não tivessem nenhum fim, Deus enquanto última causa eficiente não os faria tal como de fato são, pois Deus só age com um fim em vista. Mas precisamos também afirmar que o universo criado como um todo tem um fim único para que ele seja o que ele é como um todo?

Suarez já indicou que sim: que a experiência da beleza e da ordem harmônica do universo nos obriga a reconhecer a existência de um fim único do universo como um todo (DM 23, 10,2) $)^{17}$. Sem a existência de um fim último do universo, guiando Deus na criação do universo, não poderíamos compreender porque Ele teria ordenado as partes do universo de modo harmônico e não poderíamos explicar a beleza que nele constatamos.

Entretanto, este argumento não parece ser decisivo. Com efeito, nem todos os seres humanos compartilham desta experiência da harmonia e da beleza. Muitos seres humanos, olhando para os conflitos e as partes imperfeitas do universo, dizem que o universo lhes aparece como algo sem beleza e sem harmonia. Para estes, portanto, não é preciso postular a existência de um fim único do universo para explicar que ele seja do jeito que é (DM 24, 1, 12-13).

E mesmo reconhecendo que cada ente do universo só é o que é devido a um fim próprio, pois Deus não pode criar nada sem um fim, mesmo assim parece que não precisamos postular uma causa final única do todo. Pois

\footnotetext{
${ }^{17}$ Ver nota 14.
} 
podemos pensar que Deus criou os entes visando diversos fins separados, de modo que este grupo de entes foi criado visando um fim e que aquele outro grupo de entes foi criado visando outro fim, sem nenhum fim superior que os harmonize. Esta hipótese parece até explicar melhor a mencionada experiência da falta de harmonia e de beleza no universo (DM 24, 1, 12-13).

Suarez, entretanto, mostra que esta hipótese só seria sustentável se Deus fosse capaz de visar bens finitos como fins últimos ao criar este ou aquele conjunto de entes. Com efeito, só é possível existir vários fins últimos num universo, se cada um deles for algo finito. Não é possível a existência de diversos fins últimos infinitos, pois, sendo infinitos, eles não seriam diversos. Ora, ao criar o universo, Deus só pode ter Ele mesmo como fim último. Ele só pode criar o universo visando a um bem infinito que é Ele mesmo. Pois, se Ele criasse o universo visando somente bens finitos, ele não estaria sendo racional, por assim dizer, pois estaria escolhendo um bem menor no lugar de um bem maior. Deus criaria o universo deixando de ser Deus, o que é absurdo. Logo, ao criar o universo Deus visou como fim último algo infinito e, portanto, único. Assim, não é possível a existência de grupos de entes submetidos a fins separados sem a existência de um fim superior único. O universo criado é, portanto, necessariamente harmônico e belo, mesmo que não reconheçamos sua beleza e harmonia na 'experiência' ${ }^{\text {' }}$.

É preciso, portanto, afirmar que o universo como um todo tem um fim único, principalmente porque o contrário implica uma contradição real em Deus. Isto também explica porque o universo é do jeito que é - harmônico e belo. Mesmo que muitos seres humanos não tenham a experiência da harmonia e da beleza do universo, sabemos que elas são reais através da razão, que não pode reconhecer como real aquilo que implica em contradição. Evidentemente dizer que há um único fim no universo como um todo náo é dizer que saibamos o que é este fim e como ele se concretiza nos diversos fins particulares. Para isto teríamos que conhecer a Deus nele mesmo, o que normalmente não é possível nesta vida.

\footnotetext{
${ }^{18}$ Licet verum sit ex ipsis rebus quas creat, quasdam ordinare ad alias ut ad fines, vel potius omnes inter se connectere ut alias aliis vicisim deserviant, atque hoc modo sub ipso Deo assignari possint alii fines communes vel universales ad quos singulae creaturae, praeter privatos fines, ordinantur ab ipsomet creatore, et praesertim ad ordinem vel pulchritudem universi, tamen simpliciter nullus extra Deum potest dici finis ultimus in quem divina intentio seu actio tendit. (DM 24,1,15). Agens, quo perfectius et universalius, eo intendit in perfectionem et universaliorem finem; Deus autem est perfectissimum et universalissimum agens; ergo intendit perfectisssimum et universalissimum finem. (DM 24, 1, 14).
} 


\section{CONCLUSÁO}

Nas disputas 23 e 24 das Disputationes metaphysicae encontramos elementos favoráveis àquela interpretação de Suarez que diz que ele não reconhece a realidade da causa final no 'reino da natureza não-intencional' e que há nele uma redução da causa final à sua presença intencional na mente de um agente racional e, por analogia, em Deus. ${ }^{19}$ Pois ele diz que só podemos falar de causalidade final nos agentes naturais na medida em que os efeitos próprios de cada um deles foram determinados em última instância por Deus e que Nele podemos reconhecer por analogia uma certa intencionalidade racional e que náo podemos falar de causalidade final nestes entes na medida em que eles são a causa próxima de seus efeitos (DM 23, 10, 4). Parece, portanto, que para ele só há causa final onde há conhecimento e intenção voluntária do fim e que não há verdadeiramente causa final nos entes sem intelecto e sem vontade livre.

Mas também encontramos elementos que indicam que esta interpretação não é incontestável. Suarez diz que em cada causa eficiente está presente um fim próprio, que faz com que ela seja determinada a produzir determinado efeito. É o fim que dá identidade à causa eficiente ${ }^{20}$. Não há, portanto, para ele uma primazia absoluta da causa eficiente sobre a causa final, pelo contrário, sob certo aspecto há uma primazia do fim sobre a causa eficiente, pois é ele que determina a causalidade própria de uma causa eficiente. Para ele também há uma presença universal do fim, mesmo nos agentes naturais, pois, onde quer que haja uma causa eficiente, deve haver um fim ${ }^{21}$.

Assim, se fizermos a pergunta: "Há uma causa final em todos os entes, sem levar em consideração Deus e sua intencionalidade?”, Suarez nos ofereceria respostas contraditórias, pois afirma, por um lado, que o fim supóe uma mente capaz de conhecê-lo e querê-lo e, portanto, que não pode estar presente nos entes sem intelecto e sem vontade livre e afirma, por outro lado, que o fim está presente em todas as causas eficientes, portanto, também nos entes sem intelecto e sem vontade livre. Esta contradição, entretanto, só surge para aqueles que fizerem tal pergunta e não para ele mesmo. Para ele a própria pergunta não faria sentido, pois não há sentido em falar de uma causalidade

\footnotetext{
${ }^{19}$ Ver notas 2 e 3.

${ }^{20}$ Ver nota 8,9 e 14 .

${ }^{21}$ Ver nota 4 e 5 .
} 
própria dos entes criados sem a causalidade divina concomitante ${ }^{22}$. Assim, se lembrarmos que para ele toda operação dos entes criados é imediatamente também uma ação divina, então é possível afirmar as duas coisas sem contradição: que há um fim em todos os entes e que o fim supóe uma mente e uma intencionalidade. Por isso, aquelas interpretaçôes que falam que há nele uma presença universal do fim me parecem mais coerentes com seu pensamento do que aquelas que reduzem a presença da causa final aos entes capazes de intencionalidade consciente.

CEZAR, C. R. Final cause in the Disputationes metaphysicae of Fransico Suarez. Trans/Form/Ação, Marília, v. 42, p. 93-114, 2019. Edição Especial.

\begin{abstract}
In the Disputationes metaphysicae (disp. 23 and 24) Francisco Suarez tries to show that final cause is not a projection of human intellect, but something real in things themselves, and that it is not possible to satisfactorily explain empirical data without it. He shows how final cause operates in human beings, in God, in so-called 'natural agents', and in the universe as a whole. In fact, final cause presupposes the existence of something which is able to know an end and to direct its actions towards that end. This does not imply, however, that the end is totally absent from the operations of 'natural agents', nor that teleological explanation never makes sense for them. From a certain point of view, there is intentionality even in the operations of non-rational beings, because all nature is subject to divine action and rationality.
\end{abstract}

KeYwords: Metaphysics. Final cause. Efficient cause.

\title{
REFERÊNCIAS
}

CARRAUD, V. Causa sive ratio: La raison de la cause de Suárez a Leibniz. Paris: Presses Universitaires de France, 2002.

COLlACICCO, G. Omnis causa est princpium. Revista Filosófica de Coimbra, Coimbra, v. 23, n. 46, p. 263-292, 2014.

PENNER, S. Final causality. In: FINK, J. L. (ed.). Suarez on Aristotelian causality. Leiden; Boston: Brill. 2015. p. 121-148.

SCHMID, S. Finalursachen in der frühen Neuzeit. Berlin; New York: De Gruyter. 2011.

\footnotetext{
${ }^{22}$ Secunda sententia est Deum per se et imediate agere in omni actione creaturae, atque hunc influxum eius esse simpliciter necesssarium ut criatura aliquid efficiat. (DM 22, 1, 6).
} 
SHIELDS, Cr.; SCHWARTZ, D. Francisco Suarez. In: ZALTA, E. N. (ed.). Stanford Encyclopedia of Philosophy. Stanford: CSLI Stanford University, 2016. (Winter Edition).

SUAREZ, F. Disputationes metaphysicae. Edited Salvador Castellote. Disponível em: $<$ http://homepage.ruhr-uni-bochum.de/Michael.Renemann/suarez/>. Acesso em: 05 jul. 2018.

Recebido: 30/12/2019

Aceito: 30/12/2019 
CEZAR, C. R. 